\title{
Caracterización de datos catastrales para la tipificación de asentamientos informales en Medellín
}

\section{Characterization of cadastral data for the classification of informal settlements in Medellín}

\author{
Daniela Guerra-Ocampo $^{1 \mathrm{a}}$, Julián Castillo ${ }^{1 \mathrm{~b}}$, Yony Ceballos ${ }^{1 \mathrm{c}}$ \\ ${ }^{1}$ Grupo de Ingeniería y Sociedad, Facultad de Ingeniería, Universidad de Antioquia, Colombia. \\ Correo electrónico: a daniela.guerrao@udea.edu.co, b jandres.castillo@udea.edu.co, ${ }^{\mathrm{c}}$ yony.ceballos@udea.edu.co \\ Recibido: 1 febrero, 2018. Aceptado: 22 agosto, 2018. Versión final: 4 septiembre, 2018.
}

\begin{abstract}
Resumen
Este documento propone por medio de un análisis estadístico, identificar las condiciones actuales de los asentamientos en las comunas de Medellín y extraer información a partir de los datos para comprender las condiciones que hacen llamativo para los desplazados asentarse en tales zonas. El presente estudio se soporta en información proporcionada por la Subsecretaría de Catastro de Medellín, la cual corresponde a la cantidad de predios informales existentes, su comuna, así como datos de suelo, condiciones viales, áreas, estratos socio-económicos, tipos de zona física, entre otras que permitan analizar las condiciones iniciales para que las personas que emigran definan su asentamiento. Además, permite conocer las tendencias en la ciudad en cuanto al estrato o nivel de vida que poseen las personas, así como hacer un diagnóstico del estado actual en cuanto a predios, comunas, barrios existentes, división del territorio, condiciones viales, usos asignados al suelo, cantidad de pisos o cantidad de propietarios de los predios, entre otros, que evidencien los comportamientos de la sociedad colombiana; finalmente muestra relaciones entre la variable clase de suelo con el estrato, jerarquía y estado vial.
\end{abstract}

Palabras clave: asentamientos informales; estadística descriptiva; predios; catastro; Minitab®.

\begin{abstract}
This document proposes, through a statistical analysis, to identify the current conditions of the settlements in the communes of Medellin and extract information from the data to understand the conditions that make it attractive for displaced people to settle in. This study is supported by information provided by the Cadastre secretary of Medellin, which corresponds to the number of existing informal properties, their commune, as well as data on soil, road conditions, areas, socio-economic level, area types, among others that allow to analyse the initial conditions so that people who emigrate define their settlement. In addition, this analysis allows to know the trends in the city regarding the level of life that people possess, as well as to make a diagnosis of the current state in terms of properties, communes, existing neighbourhoods, division of the territory, road conditions, uses assigned to the soil, number of floors or number of owners of the properties, among others, which evidences the behaviour of Colombian society. Finally, relations between the soil class variable and the stratum, hierarchy and road state.
\end{abstract}

Keywords: informal settlements; descriptive statistics; building; cadaster; Minitab ®.

ISSN impreso: 1657 - 4583, ISSN en línea: 2145 - 8456, CC BY-ND 4.0 (c) () ()

Como citar: D. Guerra-Ocampo, J. Castillo, Y. Ceballos, "Caracterización de datos catastrales para la tipificación de asentamientos informales en Medellín,” Rev. UIS Ing., vol. 18, no. 1, pp. 187-202, 2019. doi: 10.18273/revuin.v18n1-2019017 


\section{Introducción}

Según la Organización para el Desarrollo y la Cooperación Económica OECD (Organisation for Economic Co-operation and Development), los asentamientos informales son áreas en las que se han construido grupos de viviendas en un terreno en el cual los ocupantes no tienen derecho legal o lo ocupan ilegalmente. También se entienden como asentamientos no planificados y zonas donde la vivienda no está de acuerdo con el planeamiento vigente y las normas de construcción (vivienda no autorizada) [1].

Para conocer la dinámica de los asentamientos es necesario realizar un análisis estadístico, así como la contribución y relación de cada una de las variables al problema descrito. La información de los predios se soporta en información proporcionada por el Municipio de Medellín en cuanto a la base de datos catastral alfanumérica y geográfica, dicha información es proporcionada por la Subsecretaría de Catastro que como dueña de ésta solicita al presente estudio cumplir con todos los lineamientos establecidos por la Ley 1266 de 2008 (Colombia) más conocida como ley Habeas Data, que define la protección de los datos personales de los contribuyentes. La Subsecretaría de Catastro de Medellín como ente regidor de los datos catastrales posee información de propietarios, direcciones e información física que no será publicada en el presente documento.

En este artículo se analizan los datos catastrales empleando estadística descriptiva para extraer información, comprender las situaciones que éstos representan e identificar la dinámica de los asentamientos desde el componente estadístico [2], [3]. También se identifica la contribución de cada una de las variables para que aparezcan los asentamientos y las relaciones existentes entre las variables analizadas.

\section{Metodología de recolección de datos}

Para la selección de datos a tener en cuenta en el modelo, se llevó a cabo el siguiente procedimiento: Una vez obtenida la base de datos catastral con corte al primero de enero de 2017 se realiza la consulta de los predios informales resultando 79.477. En primer lugar, se eliminan aquellos que no tengan información geoespacial, es decir predios sin ubicación geográfica definida los cuales reúnen un total de 5.870. Luego de la primera eliminación quedan 73.607 y se realiza la segunda eliminación, predios que no tengan información de zona homogénea física, es decir aquellos que tengan las caracterizaciones de codificación de Zona Homogénea Física detallada posteriormente, los cuales reúnen un total de 5.332. Luego de la segunda eliminación quedan 68.275 y se realiza la tercera eliminación, predios sin estratificación, es decir se eliminan todos los predios que no correspondan a predios residenciales o que no posean estratificación, los cuales reúnen un total de 2.217. Luego de la tercera eliminación quedan 66.058 predios de los cuales se realiza una cuarta eliminación, predios sin información de construcción, los cuales reúnen un total de 3.140. Finalmente, después de la cuarta eliminación quedan 62.918 , siendo este número el valor final de predios válidos para el presente estudio.

Tabla 1. Selección de datos (predios informales) a analizar.

\begin{tabular}{|l|r|}
\hline \multicolumn{1}{|c|}{ Condiciones } & Cantidad \\
\hline Datos iniciales & 79.477 \\
\hline Sin información geoespacial & -5.870 \\
\hline Sin información de zona homogénea & -5.332 \\
\hline Sin estratificación & -2.217 \\
\hline Sin información de construcción & -3.140 \\
\hline Datos finales & 62.918 \\
\hline
\end{tabular}

Fuente: elaboración propia.

En la tabla 1, se evidencia la eliminación de los datos que no cumplen las características descritas.

A continuación, se expondrán las variables con las que se cuenta en la base datos y posteriormente, se identificarán las relaciones entre variables identificadas. Para efectos de la modelación, es importante identificar variables físicas, que puedan ser representadas en el modelo formal.

\section{Resultados}

Los datos alfanuméricos proporcionados por la Subsecretaría de Catastro serán representados por medio de técnicas visuales, que permitan el entendimiento de los comportamientos propios a la naturaleza de cada variable. Para abordar las variables a estudiar se dividirán en dos tipos: variables de identificación o información y variables de análisis [2]-[4].

\subsection{Variables de análisis}

Son las variables que representan condiciones medibles y cuantificables. Este tipo de variable a su vez fue clasificado en cualitativas o cuantitativas.

\subsubsection{Variables cualitativas}

Son las variables que expresan distintas cualidades, características o modalidad. Cada modalidad que se presenta se denomina atributo o categoría y la medición consiste en una clasificación de dichos atributos. La característica que miden de la unidad de análisis es una cualidad, este tipo de variables suele estar 
compuesta por categorías. Las variables estudiadas son politómicas debido a que pueden adquirir tres o más valores.

\subsubsection{Comuna}

Se entiende como una subdivisión administrativa menor que corresponde a una zona urbana, rural, o mixta. Es equivalente al municipio o concejo $\mathrm{u}$ otras instancias de administración local. En Colombia, Comuna es un término usado para referirse a una unidad administrativa del área urbana de una ciudad media o principal del país, que agrupa sectores o barrios determinados. La mayoría de las ciudades capitales están divididas en comunas [5]. La ciudad de Medellín esta seccionada en 16 comunas como se muestra en la figura 1.

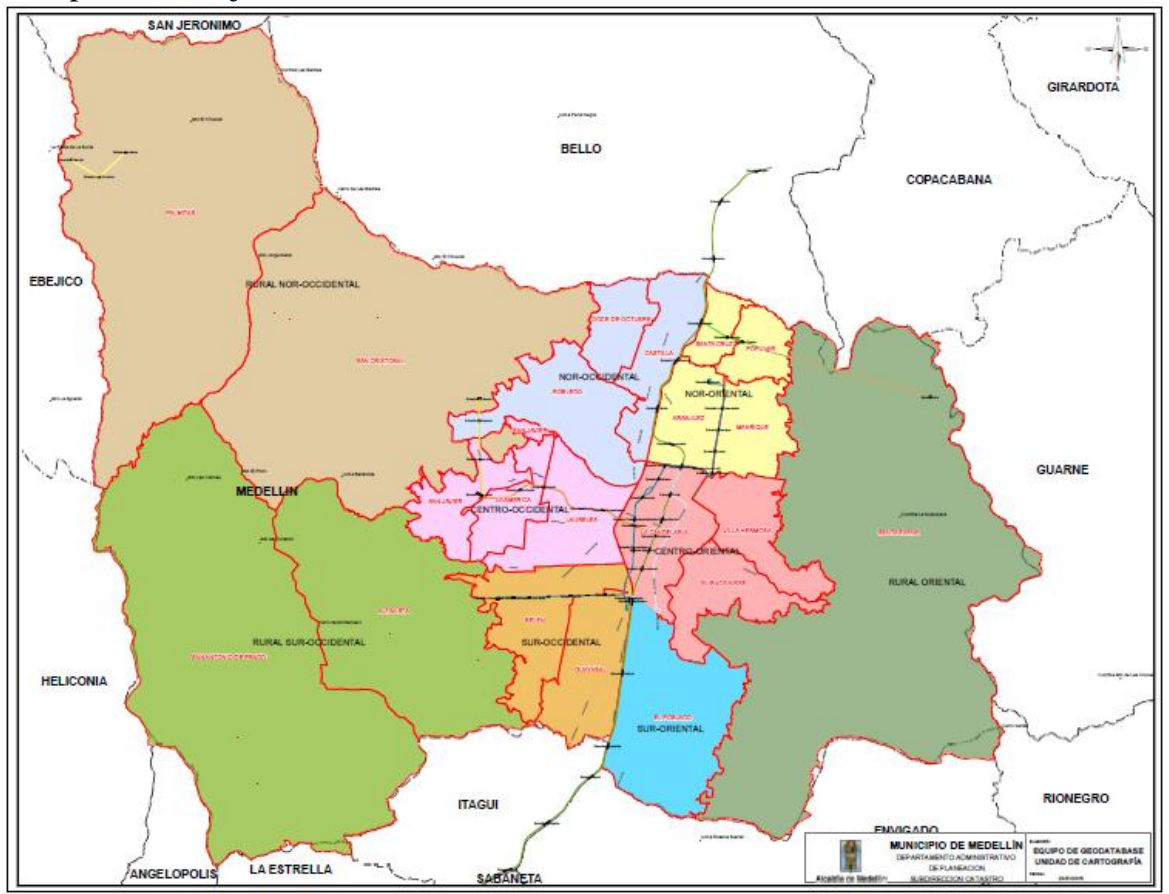

Figura 1. Comunas en la ciudad de Medellín. Fuente: Alcaldía de Medellín.

Las comunas son creadas por los concejos municipales de cada ciudad, por los concejos distritales o los concejos metropolitanos de acuerdo a las propias necesidades de la población y el territorio que habitan. La creación de comunas define la administración de los servicios que se brindan a una población urbana determinada. En la figura 2 se puede observar que las comunas con mayores frecuencias son Popular, Villa Hermosa y Manrique, quienes poseen alta cantidad de predios, es decir, cuentan con mayores volúmenes de viviendas informales.

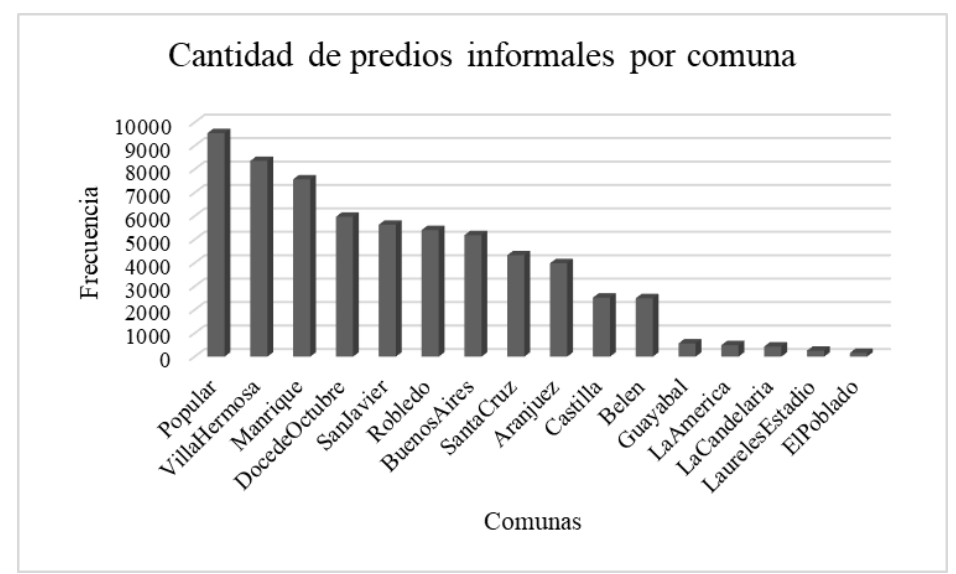

Figura 2. Cantidad de asentamientos informales por comuna. Fuente: elaboración propia. 


\subsubsection{Barrio}

Se denomina a la unidad geográfica urbana conformada por un número determinado de predios pertenecientes a una o varias manzanas [6]. Los barrios representan subdivisiones de las comunas. En [7], [8] se pueden observar las subdivisiones de los barrios en la ciudad de Medellín. También se muestran cada una de las separaciones por comuna, así como la clasificación de los barrios en la ciudad. Y finalmente, de forma geográfica se muestran los mapas por zonas que contienen las separaciones barriales explicados en las tablas anteriores, por ejemplo:

- Zona Centro Occidental: La América, San Javier, Laureles.

- Zona Centro Oriental: La Candelaria, Villa Hermosa, Buenos Aires.

- Zona Nor-Occidental: Doce de Octubre, Castilla, Robledo.

- Zona Nor-Oriental: Santa Cruz, Popular, Aranjuez, Manrique.

- Rural Nor-Occidental: Palmitas, San Cristobal.

- Zona Rural Oriental: Santa Helena.

- Zona Rural Sur-Occidental: San Antonio de Prado.

- Zona Sur-Occidental: Belén, Guayabal.

- Zona Sur-Oriental: El Poblado.

\subsubsection{Estrato}

Es la localización de un predio, proyecto u obra y que responde a una ubicación socioeconómica. La estratificación socioeconómica es una clasificación en estratos de los inmuebles residenciales que deben recibir servicios públicos. Se realiza principalmente para cobrar de manera diferencial por estratos los servicios públicos domiciliarios permitiendo asignar subsidios y cobrar contribuciones en esta área. De esta manera, quienes tienen más capacidad económica pagan más por los servicios públicos y contribuyen para que los estratos bajos puedan pagar sus tarifas [9].

Los estratos socioeconómicos en los que se pueden clasificar las viviendas y/o los predios son 6 , creados por la ley 142 de 1994 y denominados según la tabla 2.

De éstos, los estratos 1 y 2 corresponden a estratos bajos que albergan a los usuarios con menores recursos, los cuales son beneficiarios de subsidios en los servicios públicos domiciliarios; los estratos 5 y 6 corresponden a estratos altos que albergan a los usuarios con mayores recursos económicos, los cuales deben pagar sobrecostos (contribución) sobre el valor de los servicios públicos domiciliarios. El estrato 4 no es beneficiario de subsidios, ni debe pagar sobrecostos, paga exactamente el valor que la empresa defina como costo de prestación del servicio [10].

Tabla 2. Denominación de estrato.

\begin{tabular}{|l|l|}
\hline Estrato & Denominación \\
\hline 1 & Bajo-bajo \\
\hline 2 & Bajo \\
\hline 3 & Medio-bajo \\
\hline 4 & Medio \\
\hline 5 & Medio-alto \\
\hline 6 & Alto \\
\hline
\end{tabular}

Fuente: elaboración propia.

Tabla 3. Cantidad de predios informales por estrato.

\begin{tabular}{|l|r|r|}
\hline Estrato & Valores & Porcentaje \\
\hline 1 & 27.276 & $43,35 \%$ \\
\hline 2 & 30.262 & $48,10 \%$ \\
\hline 3 & 4.325 & $6,87 \%$ \\
\hline 4 & 720 & $1,14 \%$ \\
\hline 5 & 284 & $0,45 \%$ \\
\hline 6 & 51 & $0,08 \%$ \\
\hline Total & 62.918 & $100,00 \%$ \\
\hline
\end{tabular}

Fuente: elaboración propia.

En la tabla 3 se observa que la mayor cantidad de predios informales en la ciudad de Medellín pertenecen a los estratos 1 y 2 , en ellos se encuentra concentrado el $91,45 \%$ de los asentamientos informales totales. En la tabla se identifica además que a medida que van ascendiendo los estratos se evidencia la disminución en la cantidad de predios, con lo que se puede concluir que los accesos a estratos mayores lo logran menores cantidades de personas en la ciudad.

\subsubsection{Tipo de predio}

En Medellín, el $97 \%$ de los predios informales pertenecen a la categoría de tipo Residencial y la cantidad restante es no residencial.

\subsubsection{Descripción de usos}

Es la actividad que se desarrolla en un determinado espacio geográfico en el momento de la elaboración del estudio de zonas homogéneas físicas. Corresponde entonces a la actividad económica que se le está dando a la construcción en un predio al momento de su reconocimiento (visita de campo por parte de la oficina de catastro). Así mismo, es la destinación que se le da a los elementos materiales de la estructura urbana en las distintas actividades ciudadanas. Cuando el predio no tiene construcción, el uso de predio es lote, cuando el predio tiene construcción el uso puede ser: residencial, Comercial e Industrial [11]. 
Se muestran las cantidades correspondientes a las actividades destinadas a los predios, donde se evidencia nuevamente que el $97 \%$ se debe a usos Residenciales. (Ver tabla 4)

Tabla 4. Descripción de uso para los predios.

\begin{tabular}{|l|r|}
\hline Descripción de uso predio & Cantidad \\
\hline Residencial & 61.069 \\
\hline Comercial y Servicios & 1.038 \\
\hline Equipamientos & 582 \\
\hline Industrial & 184 \\
\hline Complementarios & 23 \\
\hline Recreativo y Deportivo & 17 \\
\hline Lotes & 5 \\
\hline
\end{tabular}

Fuente: elaboración propia.

\subsubsection{Descripción del tipo de predio}

En la tabla 5, se exponen categorías más segmentadas según los tipos de predio expuestos en la tabla 4 para clarificar como están conformados esos tipos de usos.

Tabla 5. Descripción del tipo de predio, con el tipo de uso para los predios.

\begin{tabular}{|c|c|c|}
\hline Tipo de predio & Cantidad & Uso \\
\hline Local unifamiliar & 32 & \multirow{6}{*}{$\begin{array}{l}\text { Comercial y } \\
\text { servicios }\end{array}$} \\
\hline Local unifamiliar transición & 56 & \\
\hline Locales & 14 & \\
\hline Oficinas y consultorios & 2 & \\
\hline $\begin{array}{l}\text { Oficinas y consultorios } \\
\text { unifamiliar transición }\end{array}$ & 4 & \\
\hline Parqueadero & 2 & \\
\hline Bibliotecas & 1 & \multirow{6}{*}{ Equipamientos } \\
\hline $\begin{array}{l}\text { Colegios, Universidades y } \\
\text { Centros Educativos }\end{array}$ & 16 & \\
\hline $\begin{array}{l}\text { Estaciones de metro, } \\
\text { metrocable }\end{array}$ & 1 & \\
\hline Iglesias y templos & 11 & \\
\hline Salón comunal y parroquial & 6 & \\
\hline $\begin{array}{l}\text { Servicios públicos (tanques } \\
\text { de agua) }\end{array}$ & 1 & \\
\hline Bodegas, Industria y Talleres & 9 & Industrial \\
\hline Coliseos & 1 & \multirow{2}{*}{$\begin{array}{l}\text { Recreativo y } \\
\text { deportivo }\end{array}$} \\
\hline Parques (construcciones) & 1 & \\
\hline Casa cural & 6 & \multirow{4}{*}{ Residencial } \\
\hline $\begin{array}{l}\text { Multifamiliar (4pisos en } \\
\text { adelante) usado }\end{array}$ & 27 & \\
\hline $\begin{array}{l}\text { Multifamiliar (4pisos en } \\
\text { adelante) progresivo }\end{array}$ & 125 & \\
\hline Unifamiliar (1 a 3 pisos) & 9.230 & \\
\hline
\end{tabular}

Fuente: elaboración propia.
Para la tabla 5 se tomó una muestra que permitiera conocer los tipos de predio que se presentan en la ciudad y a su vez, comprender el uso que se le da a los mismos.

\subsubsection{Suelo}

Constituido por las áreas del territorio municipal destinadas a usos urbanos, rurales, expansión o suburbanos. En Medellín se tiene un alto volumen de suelo Urbano, específicamente 55.089 (87,6 \%) de los predios informales estudiados y tan sólo 7.829 (12,4\%) de los predios son en suelo Rural. Estas a su vez, obtienen una clasificación adicional: Protegido y No protegido.

Suelo de Protección: Constituido por las zonas y terrenos localizados dentro de cualquiera de las anteriores clases, que, por sus características geográficas, paisajísticas o ambientales, o por formar parte de las zonas de utilidad pública para la ubicación de infraestructura para la provisión de servicios públicos domiciliarios o de las áreas de amenaza y riesgo no mitigable para la localización de asentamientos humanos, tiene restringida la posibilidad de urbanizarse [12]. En la tabla 6 se presentan las circunstancias por las que un área es protegida en la ciudad.

Tabla 6. Categorías de los suelos protegidos, en Medellín.

\begin{tabular}{|l|l|}
\hline Usos del suelo & Categoría \\
\hline \multirow{4}{*}{ Áreas Protegidas } & Áreas de aptitud Forestal \\
\cline { 2 - 2 } & $\begin{array}{l}\text { Áreas de Protección a nacimientos de } \\
\text { corrientes naturales de agua }\end{array}$ \\
\cline { 2 - 2 } & Retiros a corrientes naturales de agua \\
\cline { 2 - 2 } & Zonas de alto riesgo no recuperable \\
\cline { 2 - 2 } & Zonas de riego recuperable \\
\cline { 2 - 2 } & $\begin{array}{l}\text { Áreas de reserva para la ubicación de } \\
\text { servicios públicos }\end{array}$ \\
\cline { 2 - 2 } & Reservas de la Sociedad Civil \\
\hline
\end{tabular}

Fuente: elaboración propia.

En el anexo 1 se detallan cada una de las categorías de la tabla 6.

\subsubsection{Clase de suelo}

Según el Departamento de Planeación del municipio de Medellín los suelos se clasifican en suelo urbano, rural, de expansión y suburbano (Definido por el POT Acuerdo 46 de 2006 y redefinido y mejorado por acuerdo $48 \mathrm{de}$ 2014).

El suelo urbano tiene las siguientes características: Las áreas destinadas a usos urbanos que dispongan de infraestructura vial y redes primarias de acueducto, energía y alcantarillado, y sea posible urbanizarlos o 
construirlos. Algunas zonas con procesos de urbanización incompletos, comprendidos en áreas Consolidadas con edificación, que se definan como áreas de mejoramiento integral y zonas de alto riesgo recuperable o mitigable que serán objeto de acciones de mitigación.

También se clasifican como suelo urbano las áreas centrales de San Antonio de Prado, San Cristóbal que reúnen las anteriores características.

Los terrenos rurales son considerados no aptos para el uso urbano, por su destinación a usos agrícolas, ganaderos, forestales, de explotación de recursos naturales y actividades análogas, así como usos recreativos. En concordancia con lo anterior, el área rural excluye de esta denominación las áreas urbanas y las de expansión. Al interior del suelo rural se delimitan las clases de suelo de protección y suelo suburbano. Existen igualmente zonas de riesgo mitigable al interior de estas clases, para las cuales deberán llevarse a cabo las correspondientes obras de mitigación para que puedan ser desarrollados.

Se define como suelo de expansión el constituido por la porción del territorio municipal que se habilitará para el uso urbano durante la vigencia del Plan de Ordenamiento, según lo determinen los programas de ejecución. La determinación de este suelo se ajustará a las previsiones de crecimiento de la ciudad y a la posibilidad de dotación con infraestructura para el sistema vial, de transporte, de servicios públicos domiciliarios, áreas libres y parques y equipamiento colectivo de interés público o social.

Dichos suelos podrán ser urbanizados y construidos simultáneamente, según el caso, para dotarlos de infraestructura vial, de transporte, servicios públicos domiciliarios, áreas libres, parques y equipamiento colectivo de interés público o social, utilizando para este fin los procedimientos e instrumentos que establece la ley y el Plan de Ordenamiento Territorial.

Las áreas de expansión del Municipio de Medellín se localizan al occidente de la ciudad en los sectores de Pajarito, El Rincón, Altos de Calasanz, Eduardo Santos, El Noral, AltaVista y en el Corregimiento de San Antonio de Prado.

Constituyen categoría de suelo suburbano las áreas ubicadas dentro del suelo rural, en las que se mezclan los usos del suelo y las formas de vida del campo y la ciudad, que pueden ser objeto de desarrollo con restricciones de uso, de intensidad y de densidad, garantizando el autoabastecimiento en servicios públicos domiciliarios, de conformidad con lo establecido en la Ley 99 de 1.993 y la Ley 142 de 1.994.

Forman parte de esta categoría los corredores urbanos interregionales. El suelo suburbano incorpora parte de las siguientes veredas:

- Corregimiento de Santa Elena: Barro Blanco, Piedra Gorda, El Placer, Santa Elena Central, El Cerro, El Llano, El Plan, Piedras Blancas- Matasano, Las Palmas (El Mirador de El Poblado, El Tesoro y Chacaltaya).

- Corregimiento de San Cristóbal: Pedregal Alto, Travesías, El Llano, La Loma, La Cuchilla, Playas, La Palma, El Patio, El Uvito.

- Corregimiento de Altavista: El Corazón-El Morro, Aguas Frías, San Pablo, Altavista, La Esperanza, Patio Bonito, El Jardín y San José del Manzanillo.

- Corregimiento de Palmitas: Urquitá, La Aldea, Potrera-Miserenga, y Palmitas Central.

- Corregimiento de San Antonio de Prado: Potrerito.

De acuerdo con las clases de suelo descritas anteriormente se plantea la tabla 7 en la que se evidencian las cantidades existentes de cada una de las clasificaciones del suelo en la ciudad de Medellín, teniendo en cuenta las características de protección. También se muestran de a pares los tipos de suelo con su clasificación protegido o no. Se puede verificar entonces, que la mayor parte del suelo en Medellín está siendo utilizado como espacio Urbano, ya sea Urbano no protegido en el que se ubican viviendas o Urbano protegido, como lo es el Jardín Botánico, por ejemplo.

Tabla 7. Descripción de la clase de suelo en la ciudad de Medellín, por número de predios.

\begin{tabular}{|l|r|l|r|}
\hline \multicolumn{4}{|c|}{ Tipo de predio - clase de suelo } \\
\hline No protegido & 256 & Expansión & 179 \\
\hline Expansión & 763 & Rural & 4.170 \\
\hline Rural & 2.066 & Suburbano & 791 \\
\hline Suburbano & 31.054 & Urbano & 23.639 \\
\hline Urbano & 34.139 & Total protegido & 28.779 \\
\hline Total no protegido & \multicolumn{3}{|}{}
\end{tabular}

Fuente: elaboración propia.

\subsubsection{Topografía}

Esta variable indica la condición del relieve de la zona en estudio, normalmente es identificada mediante reconocimiento en campo, o puede utilizarse un mapa de curvas de nivel de la zona de estudio. Tales condiciones de relieve están expuestas en la tabla 8. La mayor cantidad de predios en Medellín están ubicados en 
terrenos inclinados, ya sean ligeramente inclinados (entre 11 y $25 \%$ ), inclinados (entre 26 y $40 \%$ ) y ligeramente escarpado (entre 41 y $60 \%$ ), las tres clasificaciones mencionadas representan el $76,39 \%$ de los predios informales en la ciudad.

Tabla 8. Descripción topográfica, en Medellín.

\begin{tabular}{|l|r|}
\hline Topografía & Frecuencia \\
\hline Plano 0\% - 10\% & 5.478 \\
\hline Ligeramente Inclinado 11\%-25\% & 15.585 \\
\hline Inclinado 26 \% - 40\% & 14.811 \\
\hline Ligeramente Escarpado $41 \%-60 \%$ & 17.665 \\
\hline Escarpado Mayor a 60\% & 9.152 \\
\hline Sin clasificar & 227 \\
\hline
\end{tabular}

Fuente: elaboración propia.

\subsubsection{Servicios públicos}

Esta variable se refiere a la cobertura de servicios públicos presentes en el municipio en su parte urbana y de expansión, se verifica si hay existencia o no de servicios públicos domiciliarios para cada zona [12].

Se entienden por servicios públicos completos la presencia de Acueducto, Alcantarillado y Luz Eléctrica. Los servicios complementarios serian dos, la Línea Telefónica y el Gas Natural. La clasificación según la Secretaría de Hacienda, Subsecretaría de Catastro es:

- Sin Servicios: Zonas completamente desprovistas de servicios públicos domiciliarios.

- Incompletos: Zonas que solo poseen uno o dos servicios públicos.

- Completos: Zonas que poseen los tres servicios públicos básicos establecidos.

- Completos más un complementario: Comprende la categoría anterior más un servicio público complementario.

- Completos más dos complementarios: Posee todos los servicios básicos más los dos complementarios establecidos.

En la tabla 9 se muestran las cantidades de servicios públicos que posee la población de Medellín.

El 91,66 \% de los predios informales en Medellín, cuenta con los servicios públicos completos y de ello, el 91,62 \% cuenta además con servicios complementarios como telefonía y gas natural.
Tabla 9. Condiciones en servicios públicos, en Medellín.

\begin{tabular}{|l|r|}
\hline Servicios Públicos & Frecuencia \\
\hline Sin servicios & 2.459 \\
\hline Incompletos & 50 \\
\hline Completos & 21 \\
\hline Completos más un complementario & 33.886 \\
\hline Completos más dos complementarios & 23.765 \\
\hline Sin clasificar & 2.737 \\
\hline
\end{tabular}

Fuente: elaboración propia.

\subsubsection{Jerarquía vial}

Constituye la clasificación funcional de una red vial urbana. La jerarquización vial metropolitana y urbana se adopta en función de los siguientes criterios: funcionalidad, características del tránsito, tipo de transporte, continuidad de los corredores viales, articulación con la red vial nacional y conectividad entre sectores de los municipios.

Tabla 10. Jerarquía vial, en Medellín.

\begin{tabular}{|l|r|}
\hline Jerarquía Vial & Frecuencia \\
\hline Sin Vías & 8 \\
\hline Vía Férrea & 180 \\
\hline Sistema Metro Líneas A y B & 446 \\
\hline Sistema Metrocable Líneas J y K & 3.577 \\
\hline Sistema Metroplús & 116 \\
\hline Autopista Urbana & 704 \\
\hline Vías Arterias principales & 2.554 \\
\hline Vías Arterias menores & 1.419 \\
\hline Vías Colectoras & 4.180 \\
\hline Vías de servicio & 31.040 \\
\hline Vías Peatonales de Transito Urbano & 109 \\
\hline Vías Peatonales de acceso a vivienda & 14.321 \\
\hline Vías Peatonales Escalonadas & 154 \\
\hline Sin clasificar & 4.110 \\
\hline
\end{tabular}

Fuente: elaboración propia.

En el anexo 2 se explican cada una de las jerarquías de la tabla 10.

\subsubsection{Estado vial}

El estado de la vía debe ser reconocido a nivel general del barrio, teniendo como excepciones, jerarquías viales diferentes encontradas en el barrio para las que se debe reconocer el estado particularmente para estas y sectores en los cuales se observe notablemente un cambio en los estados viales que afecte la continuidad vial de la zona. [12]. En la figura 3 se presentan las categorías que contiene el estado vial en la ciudad. 


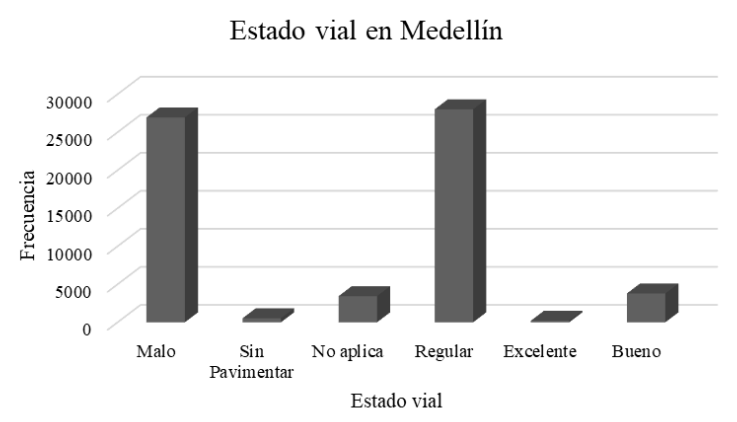

Figura 3. Estado vial, en Medellín. Fuente: elaboración propia.

En Medellín el 87,35 \% de las vías son regulares o malas, siendo estos porcentajes $44,54 \quad \%$ y $42,80 \quad \%$ respectivamente.

Según la Secretaría de Hacienda, Subsecretaría de Catastro las descripciones para las categorías son las siguientes:

- No aplica: Para el caso que no existan vías.

- Sin Pavimentar: Vías sin ningún tipo de pavimento, asfalto o adoquinería que permita un mejor tránsito vehicular o peatonal.

- Malo: Vías en un mal estado de conservación, con juntas de dilatación de tamaños considerables, quebraduras del asfalto o pavimento, $\mathrm{o}$ adoquines en muy mal estado, huecos de tamaños considerables o hundimientos y defectos notables en los trayectos, que impidan el adecuado transcurso de la marcha de los vehículos o peatones.

- Regular: Este estado aplica para aquellas vías que, aunque poseen irregularidades como las enunciadas en la categoría anterior, sus problemas no son tan acentuados y permiten un mejor y más rápido desplazamiento sobre la vía.

- Bueno: Este estado se utiliza cuando una vía es generalmente adecuada para desplazarse y no muestra ninguna de los defectos mencionados en anteriores clasificaciones, posee unas condiciones adecuadas para el rápido desplazamiento de los vehículos y las personas.

- Excelente: Para este estado se clasifican vías cuyas condiciones de asfalto, pavimentación o adoquinería, no presenta ningún tipo de deterioro y además su diseño y condiciones constructivas son óptimas.

\subsubsection{Variables cuantitativas}

La variable cuantitativa expresa cantidades, puede ser clasificada de forma continua cuando puede asumir cualquier valor numérico y de forma discreta cuando tiene valores enteros.

\subsubsection{Manzana}

Generalmente, la manzana se identifica por un espacio urbano delimitado por calles por todos sus lados, de este modo, es un código que identifica una subdivisión física existente en los sectores catastrales, separadas entre sí por vías de tránsito vehicular o peatonal y/o limitadas por accidentes naturales como cerros, acequias, ríos, etc., las que deben estar geo-referenciadas para su identificación catastral. Contiene información de loteo, acotamientos, nomenclatura vial y domiciliaria, construcción, número de pisos y sectorización. [13] En la figura 4 se elaboró un ejemplo para representar una manzana.

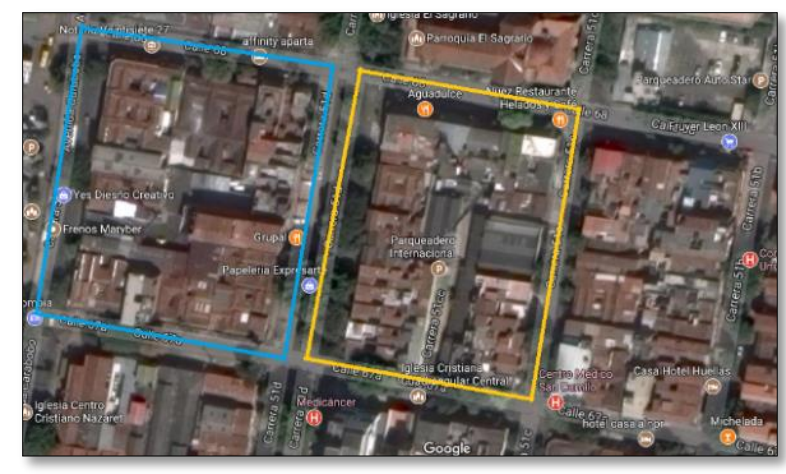

Figura 4. Ejemplos de "Manzanas" en la ciudad de Medellín. Fuente: Google maps.

Dado que las manzanas representan subdivisiones físicas territoriales, son tenidas en cuenta en el modelo basado en agentes.

\subsubsection{Lote}

Un lote representa divisiones de terreno y es la porción de tierra con una extensión geográfica definida en metros cuadrados. En la figura 5 y en la tabla 11 se observa que la cantidad de manzanas está concentrada en la parte inferior, lo que significa que normalmente los barrios tienen entre 6 y 39 manzanas, con un promedio de 35 manzanas aproximadamente.

Tabla 11. Cuartiles de la variable Manzana.

\begin{tabular}{|c|c|c|}
\hline \multicolumn{2}{|l|}{ Manzana } \\
\hline $1{ }^{\circ} \mathrm{Cuartil}$ & Media & $3^{\circ} \mathrm{Cuartil}$ \\
\hline 6 & 34,65 & 39 \\
\hline
\end{tabular}

Fuente: elaboración propia. 


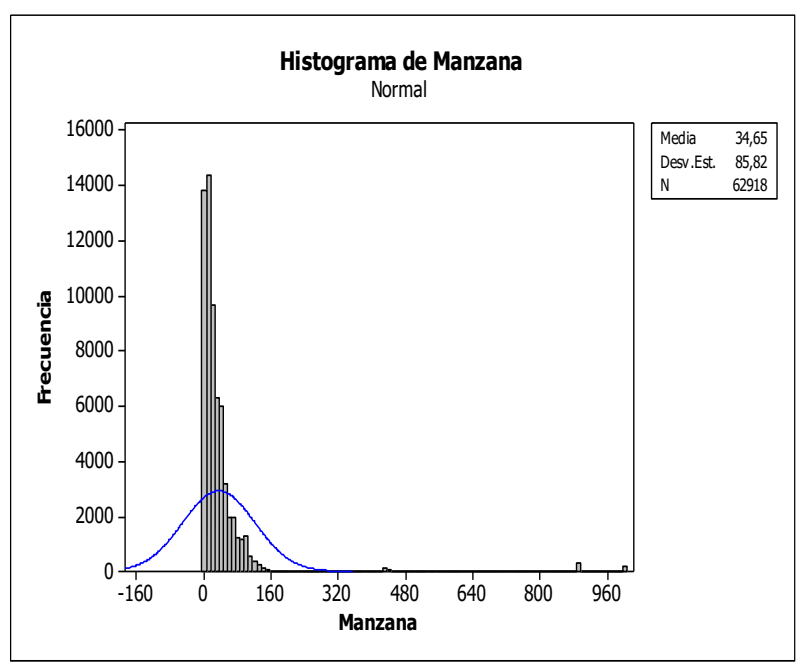

Figura 5. Cantidad de manzanas por barrio. Fuente: elaboración propia.

Sin embargo, hay presencia de datos atípicos y extremos como una sola manzana, en el caso de la Universidad de Antioquia y hasta 800 manzanas, presentado en el barrio San Javier.

Tabla 12. Cuartiles de la variable: número de lotes en las manzanas.

\begin{tabular}{|c|c|c|}
\hline \multicolumn{2}{|l|}{ Número de lotes } \\
\hline $1{ }^{\circ}$ Cuartil & Media & $3{ }^{\circ}$ Cuartil \\
\hline 11 & 34,65 & 63 \\
\hline
\end{tabular}

Fuente: elaboración propia.

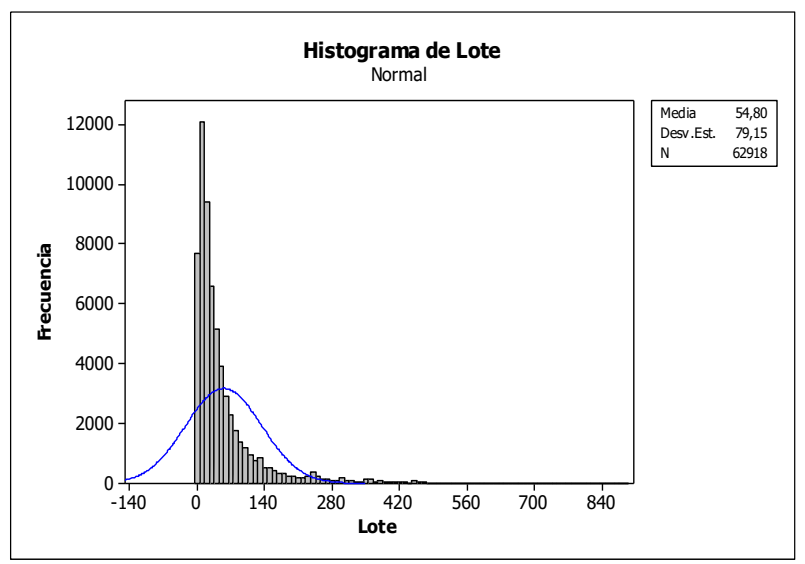

Figura 6. Número de lotes en las manzanas. Fuente: elaboración propia.

En la figura 6 y en la tabla 12 se observa que la mayoría de las manzanas en Medellín tienen de 1 a 100 lotes, con un promedio de 54,8 lotes por manzana. En cuanto al $3^{\circ}$ cuartil, el $75 \%$ de las manzanas en Medellín reúnen 63 lotes.

\subsubsection{Porcentaje de desenglobe}

Es una variable continua. El número que indica la participación porcentual que tienen derecho los poseedores o propietarios sobre las áreas comunes, cuando los inmuebles son compartidos, o se encuentran sometidos a reglamento de propiedad horizontal [11]. Definen además su participación en la asamblea de propietarios y la proporción con que cada uno contribuirá en las expensas comunes del edificio o conjunto, sin perjuicio de las que se determinen por módulos de contribución, en edificios o conjuntos de uso comercial o mixto.

Tal como se observa en la figura 7, la mayor parte de las propiedades en la ciudad de Medellín le pertenecen a un único dueño (tiene $100 \%$ de participación en su terreno), otra gran parte de las propiedades tienen un porcentaje de 0 en la participación, No representan exactamente las propiedades públicas, en estos casos corresponden como asentamientos informales a "Mejoras". Las mejoras se pueden caracterizar como:

- Mejora: Arreglos locativos que se realizan a un inmueble.

- Mejora por construcciones y/o edificaciones en predio ajeno: Es la construcción o edificación instalada por una persona natural o jurídica sobre un predio que no le pertenece.

- Mejoras: Son construcciones de uno o varios poseedores en predio ajeno y ubicado en la misma manzana catastral. Las mejoras se enumerarán secuencialmente en el plano de la manzana catastral respectivo.

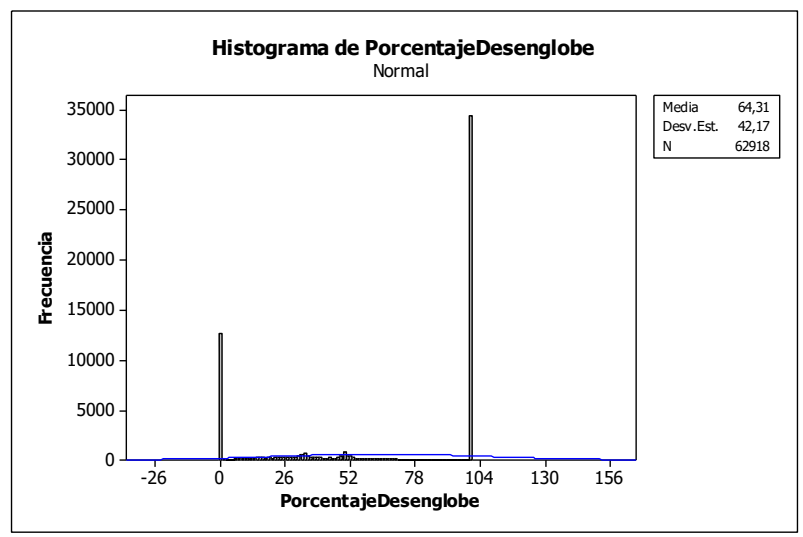

Figura 7. Porcentaje de participación porcentual de los propietarios. Fuente: elaboración propia.

\subsubsection{4. Área lote}

Es una variable continua. Representa la superficie de terreno en metros cuadrados. El área de los lotes es variada, en el sentido en que la mayor cantidad de los 
datos están concentrados en la parte inferior, lo que indica que poseen áreas de $100 \mathrm{~m}^{2}$ aproximadamente y a su vez, valores altos de alrededor de un millón de metros cuadrados. Se puede concluir entonces que en la ciudad de Medellín casi la totalidad de las construcciones no superan los $500.000 \mathrm{~m}^{2}$.

Tabla 13. Valores para áreas de lotes.

\begin{tabular}{|c|c|c|c|l|}
\hline \multicolumn{5}{|c|}{ Área Lotes } \\
\hline Mínimo & $\mathbf{1}^{\circ}$ Cuartil & Media & $\mathbf{3}^{\circ}$ Cuartil & Máximo \\
\hline 4,2 & 49,9 & 13.210 & 194,9 & $2^{2} 454.000$ \\
\hline
\end{tabular}

Fuente: elaboración propia.

De forma más simplificada se hablará de los cuartiles. Los cuartiles son los tres valores que dividen un conjunto de datos ordenados en cuatro partes porcentualmente iguales. Para ilustrar estos cuartiles, en la tabla 13 se expone el $1^{\circ}, 2^{\circ}$ (media) y $3^{\circ}$ cuartil, lo que significa: el $25 \%$ de los pedios en Medellín tienen un área de 4 a $50 \mathrm{~m}^{2}$ aproximadamente, en cuanto al $3^{\circ}$ cuartil, el $75 \%$ de los predios en Medellín tienen un área de 4 a $195 \mathrm{~m}^{2}$. La media $\left(2^{\circ}\right.$ cuartil) por su parte, guarda un porcentaje del $50 \%$ de los datos y es $13.210 \mathrm{~m}^{2}$.

Además, se identifican valores alrededor de 1millón de metros cuadrados. Estas cifras, así como el valor máximo representan lugares con áreas superiores al promedio que podrían ser debidas a: hospitales, centros comerciales, edificaciones públicas, parques recreativos y culturales, entre otros.

\subsubsection{5. Área total construida}

Es una variable continua. Es la parte edificada que corresponde a la suma de las superficies de los pisos. Excluye azoteas, áreas duras sin cubrir o techar, áreas de las instalaciones mecánicas y puntos fijos, así como el área de los estacionamientos ubicados en semisótanos, sótanos y en un piso como máximo [14]. En la tabla 14 se muestran las frecuencias para la variable.

Tabla 14. Valores para áreas construidas de lotes.

\begin{tabular}{|c|c|c|c|c|}
\hline \multicolumn{5}{|c|}{ Área Total Construida de los Lotes } \\
\hline Mínimo & $\mathbf{1}^{\circ}$ Cuartil & Media & $\mathbf{3}^{\circ}$ Cuartil & Máximo \\
\hline 0 & 40,19 & 183,1 & 161,7 & 39.290 \\
\hline
\end{tabular}

Fuente: elaboración propia.

En la variable Área total construida se tiene un comportamiento similar al de Área lote, a diferencia de que aquí, se presenta un mínimo de cero, debido a que es posible que en el área no se haya realizado ningún tipo de construcción.
En cuanto al primer cuartil, se observa que es de $40 \mathrm{~m}^{2}$, haciendo un paralelo con el área del lote, ese $25 \%$ de los predios tenía disponible para construir $50 \mathrm{~m}^{2}$, de los cuales se están utilizando $40 \mathrm{~m}^{2}$. Caso similar ocurre con el tercer cuartil, el $75 \%$ de los predios tienen un área de lote de 4,2 a $195 \mathrm{~m}^{2}$ y se está haciendo uso de 0 a $162 \mathrm{~m}^{2}$ aproximadamente. Sin embargo, la media es mucho menor porque no se tiene un máximo de área total construida tan alto.

\subsubsection{Número de pisos}

Es una variable discreta. Cada una de las superficies horizontales de las que consta un edificio.

Tabla 15. Número de pisos de los lotes.

\begin{tabular}{|c|c|c|c|c|}
\hline \multicolumn{5}{|c|}{ Número de pisos de los Lotes } \\
\hline Mínimo & $\mathbf{1}^{\circ}$ Cuartil & Media & $\mathbf{3}^{\circ}$ Cuartil & Máximo \\
\hline 0 & 1 & 2,29 & 3 & 30 \\
\hline
\end{tabular}

Fuente: elaboración propia.

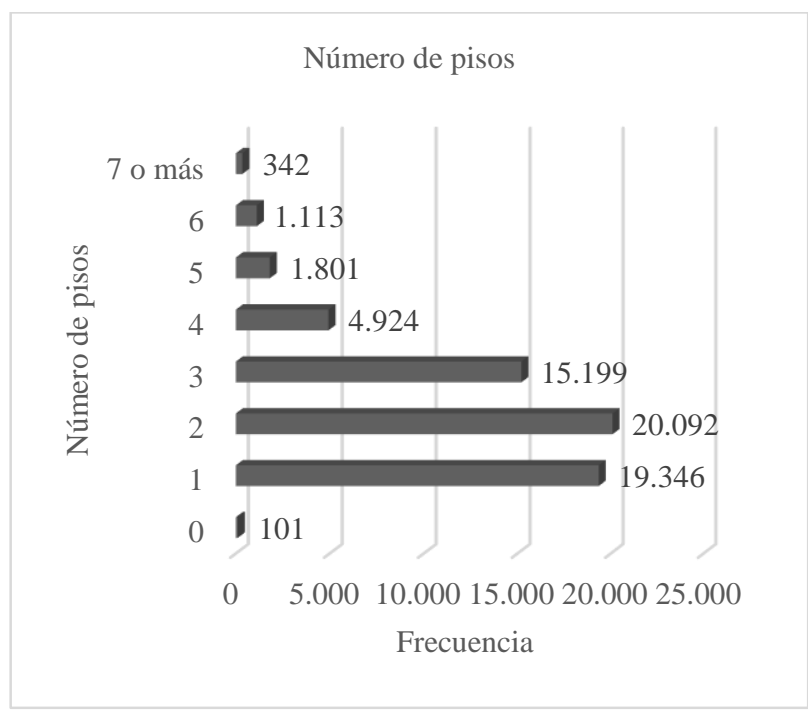

Figura 8. Número de pisos en los lotes, en Medellín. Fuente: elaboración propia.

En la figura 8 se puede observar que la mayor parte de los predios informales en la ciudad de Medellín poseen de 1 a 3 pisos. En el primer corte, el $25 \%$ de los predios cuentan únicamente con un piso, en promedio, los predios poseen 2 pisos, el $75 \%$ por tanto, tiene de 1 a 3 pisos, para finalmente, el $25 \%$ restante posee de 4 pisos en adelante.

\subsubsection{Cantidad de propietarios}

Es una variable discreta. Es el número que representa la cantidad de propietarios o poseedores relacionados con 
un predio. Este dato permite identificar a cuantas personas le pertenece un predio determinado. En el caso de una urbanización, normalmente cada piso tiene un propietario distinto, pero en conjunto, los apartamentos conforman un predio.

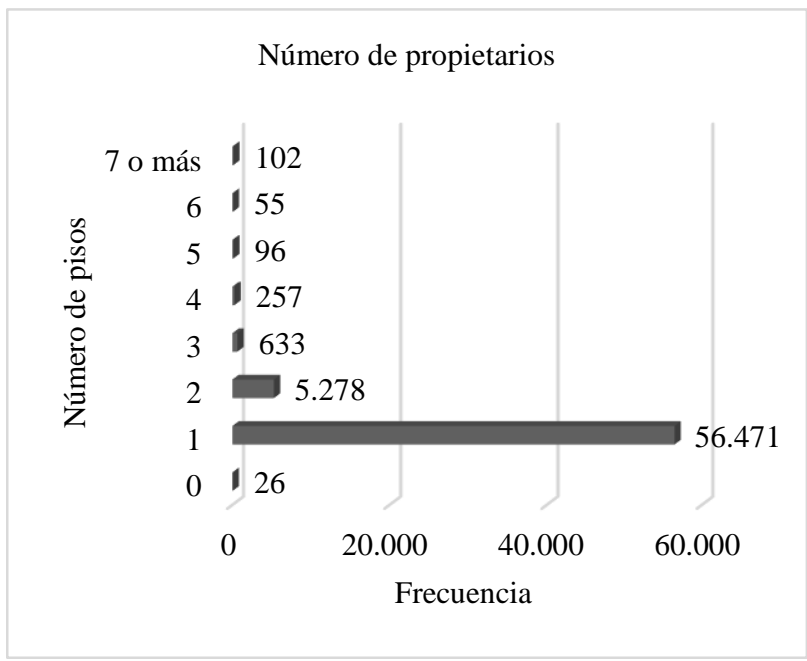

Figura 9. Número de propietarios en los predios de Medellín. Fuente: elaboración propia.

En la figura 9 se identifica que el 89,75\% de los predios informales en la ciudad de Medellín cuentan con un único propietario. Sin embargo, esta variable no propicia cambios físicos para tener en cuenta en el modelo.

\subsection{Variables de identificación e información}

En esta sección se agruparon las variables que generan una descripción o códigos de identificación que son usados por la oficina de catastro para el reconocimiento de los predios.

\subsubsection{Campo "Cobama-Lote"}

Se refiere a la unión del COBAMA (Comuna, Barrio, Manzana) y el número de lote, abreviado como "CBML". $\mathrm{Su}$ longitud es fija y se compone de 11 dígitos, siendo los 4 últimos los correspondientes al número del lote de interés dispuestos de la siguiente manera: digito 1 y 2 pertenecen a la comuna, digito 3 y 4 pertenecen al barrio, los dígitos 5, 6 y 7 pertenecen a la manzana y los dígitos 8, 9, 10 y 11 pertenecen al código del lote. Ejemplo: 01030810195

El código CBML es una variable informativa -de identificación geográfica, que proporciona la descripción de los factores mostrados en la tabla 16. Sin embargo, no es una variable propensa a modelar.
Tabla 16. Ejemplo para la variable CBML.

\begin{tabular}{|l|l|l|}
\hline Dígito & Descripción & Nombre \\
\hline 01 & Comuna 1 & Popular \\
\hline 03 & Barrio 3 de la Comuna 1 & $\begin{array}{l}\text { Santo Domingo Savio } \\
\mathrm{N}^{\circ} 2\end{array}$ \\
\hline 081 & Número de manzanas & 81 \\
\hline 0195 & Lote & $\begin{array}{l}\text { Correspondiente a los } \\
\text { predios }\end{array}$ \\
\hline
\end{tabular}

Fuente: elaboración propia.

\subsubsection{Fecha de inscripción}

En catastro, los predios elaborados por formación o actualización de la formación y los cambios individuales que sobrevengan en la conservación catastral se inscribirán en el registro catastral en la fecha de la resolución que lo ordena. Las autoridades catastrales, a solicitud de los propietarios o poseedores, certificarán sobre la inscripción catastral del predio, indicando la fecha de la vigencia fiscal del avalúo. Entiéndase como registro catastral la Base de Datos que para el efecto conformen las autoridades catastrales. Se entiende por inscripción catastral la incorporación de la propiedad inmueble en el censo catastral, dentro de los procesos de formación, actualización de la formación o conservación [15].

\subsubsection{Id Catastral}

Es el número con el que se identifica un predio en la Oficina de registro de Instrumentos Públicos y/o en el Catastro.

\section{Correlación entre variables}

En esta sección se analizarán las relaciones existentes entre las variables estudiadas. El coeficiente de correlación de Pearson expresa en qué grado los sujetos tienen el mismo orden en dos variables. Por ejemplo, si los sujetos más altos pesan más y los más bajitos pesan menos, entre peso y altura tendremos una correlación positiva: a mayor altura, mayor peso. Si los de más edad corren más despacio y los más jóvenes corren más deprisa, entre edad y velocidad tendremos una correlación negativa; a mayor edad, menor velocidad [4], [16].

El valor del coeficiente de correlación oscila entre 0 y \pm 1 ; una correlación igual a 0 significa ausencia de relación.

Los coeficientes de correlación obtenidos para el análisis de datos alfanuméricos analizados anteriormente se muestran en la tabla 17, en la que se observan valores entre 0 y 1 , donde 0 significa ausencia de relación y 1 relación fuerte entre las variables. En la diagonal de la 
tabla se encuentra la relación de la variable con ella misma, por ello el valor obtenido es 1 en todos los casos. Se concluye esa relación identificada de forma verbal, en la que se detecta la relación existente entre cada variable con ella misma y la variable Clase de suelo con tres variables: Estrato, Jerarquía vial y Estado vial.

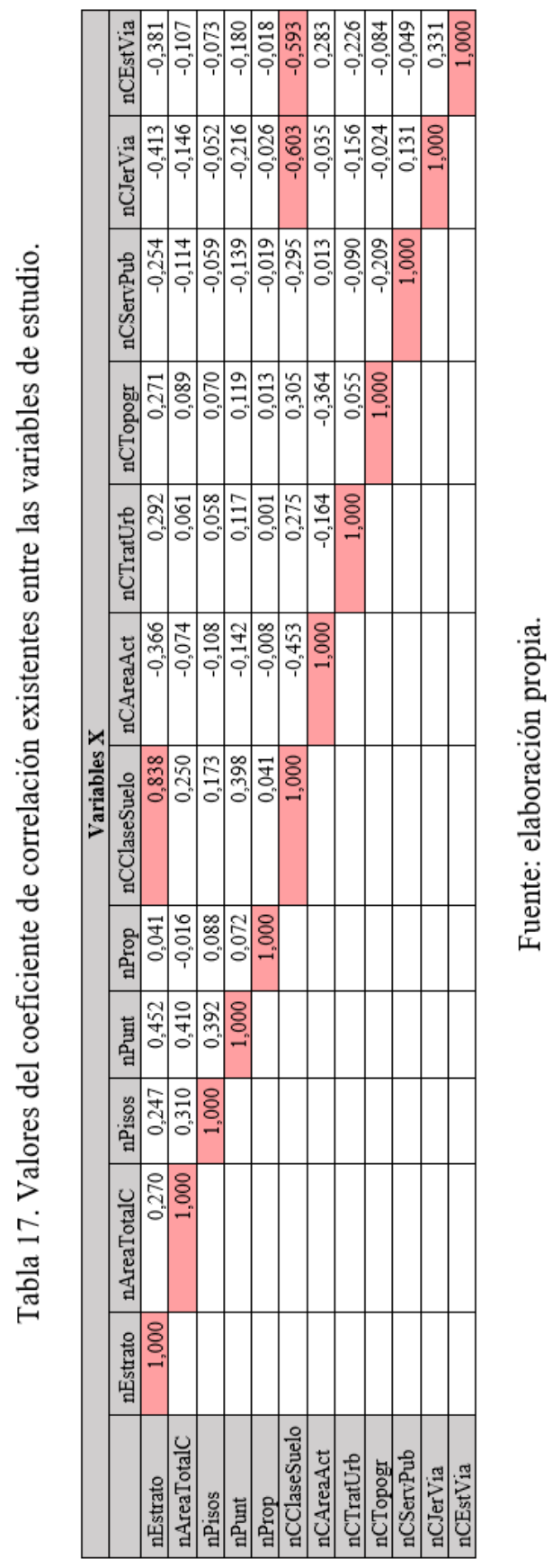

Clase de suelo - Estrato: La clase de suelo y el estrato presentan un coeficiente de correlación de $83,83 \%$. Tal índice evidencia una relación fuerte entre estas variables, con la que se concluye que efectivamente dependiendo de las clases de suelo que se tengan son definidos los estratos para los mismos.

En la figura 10 se puede observar que dependiendo de las clases de suelo con las que cuenta la ciudad de Medellín van siendo definidos los estratos para estas. Por ejemplo, 
para la mayor frecuencia presentada, dada en la variable Urbano no protegido, se tiene gran cantidad de predios con niveles de estrato 1 en su mayoría, para la categoría Urbano protegido se tiene gran cantidad de predios con niveles de estrato 2, en las zonas Rurales no protegidas se presentan en su mayoría niveles de estrato 2 y en la parte Rural protegida normalmente se tienen niveles de estrato 2 y 3.

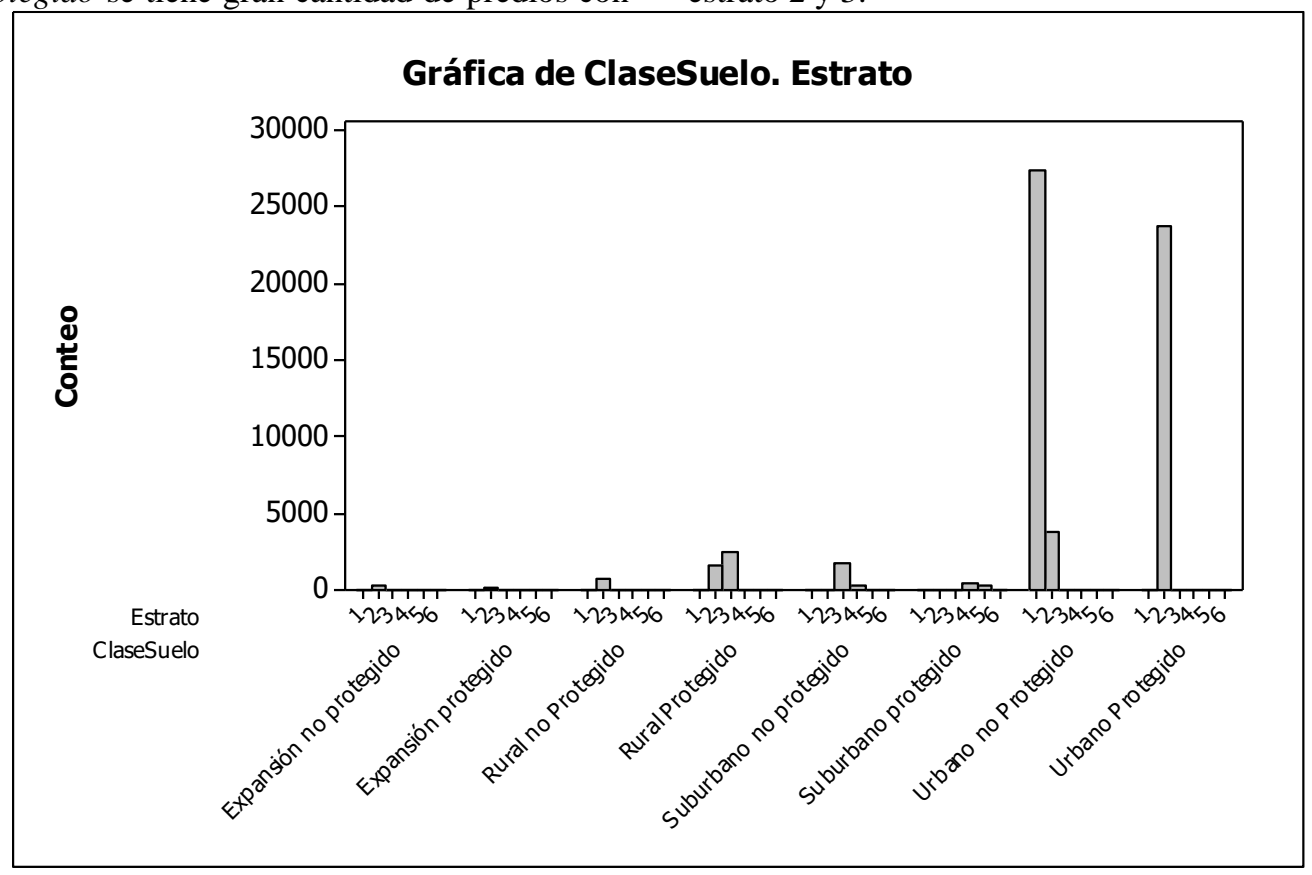

Figura 10. Relación entre Clase de suelo y Estrato, en Medellín. Fuente: elaboración propia.

Clase de suelo - Jerarquía vial: La clase de suelo y la $\quad-60,27 \%$ el cual será analizado en la figura 11. jerarquía vial presentan un coeficiente de correlación de

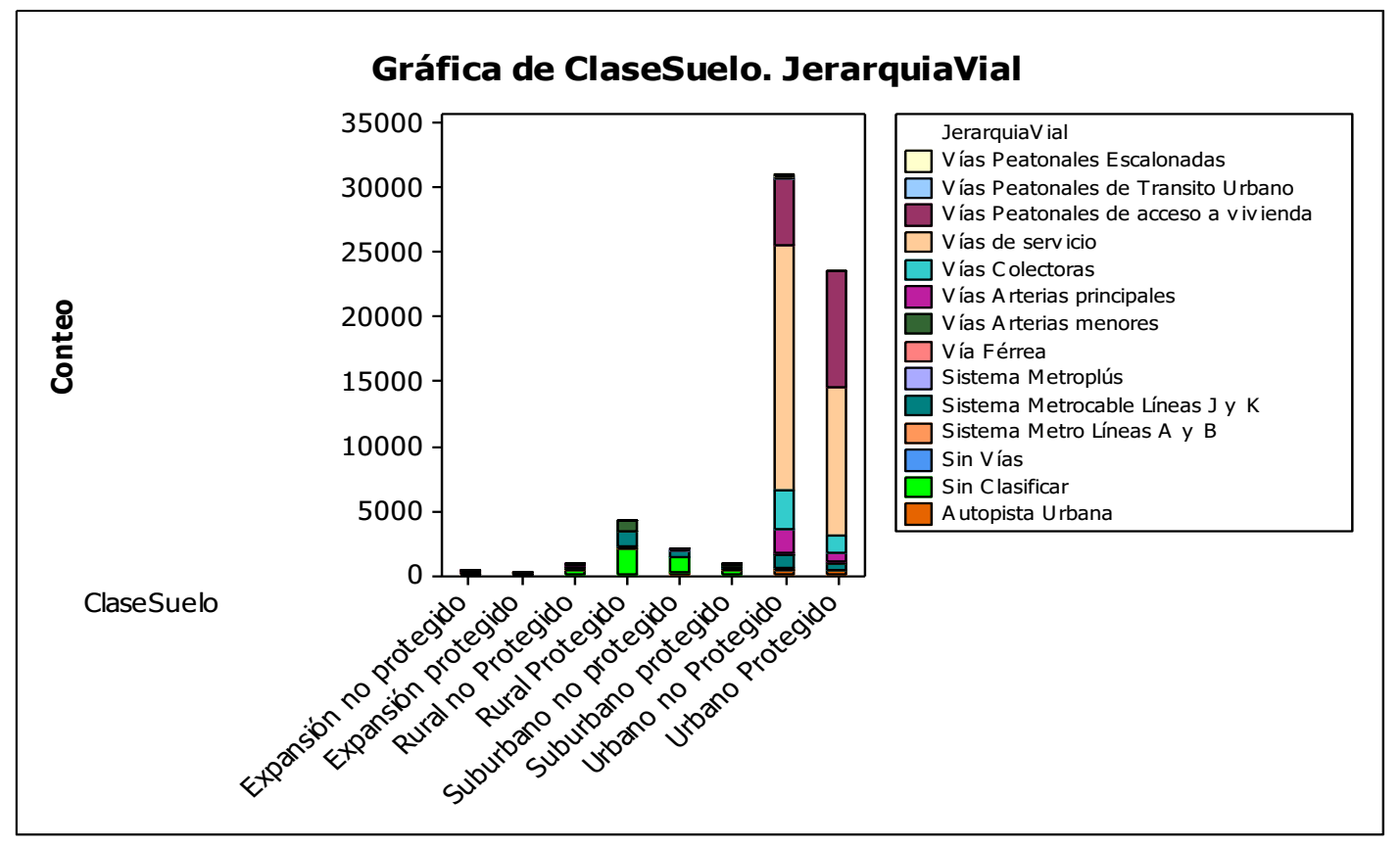

Figura 11. Relación entre Clase de suelo y Jerarquía vial, en Medellín. Fuente: elaboración propia. 
Las jerarquías viales son asignadas dependiendo de la magnitud de predios que posee cada clase de suelo. Para el caso de zonas de expansión se cuenta únicamente con pocas vías de servicios, para las zonas rurales se cuenta con secciones sin clasificar en su mayoría, vías arterías menores y sistema metrocable líneas J (san Javier) y $\mathrm{K}$ (parque Arví), finalmente para las zonas urbanas se cuenta con vías de servicio en mayor magnitud, vías peatonales de acceso a vivienda, vías colectoras, vías arterias principales y menores, sistema metrocable y autopista urbana. Además, se observa que tal jerarquía depende efectivamente de la clase de suelo estudiada.
Clase de suelo - Estado vial: La clase de suelo y el estado vial presentan un coeficiente de correlación de 59,28\% el cual será analizado en la figura 12.

El suelo de expansión cuenta con estados regulares en sus vías, las zonas rurales por su parte, en su gran mayoría un estado sin categoría, malo y sin pavimentar, el suelo suburbano presenta estados viales malos en su mayoría y algunos sectores regulares y, por último, el suelo urbano tiene gran cantidad de estados viales malos y regulares y zonas mínimas en excelente estado. La figura 12 permite ver entonces la relación que guardan las clasificaciones del suelo con las condiciones viales presentadas en los predios.

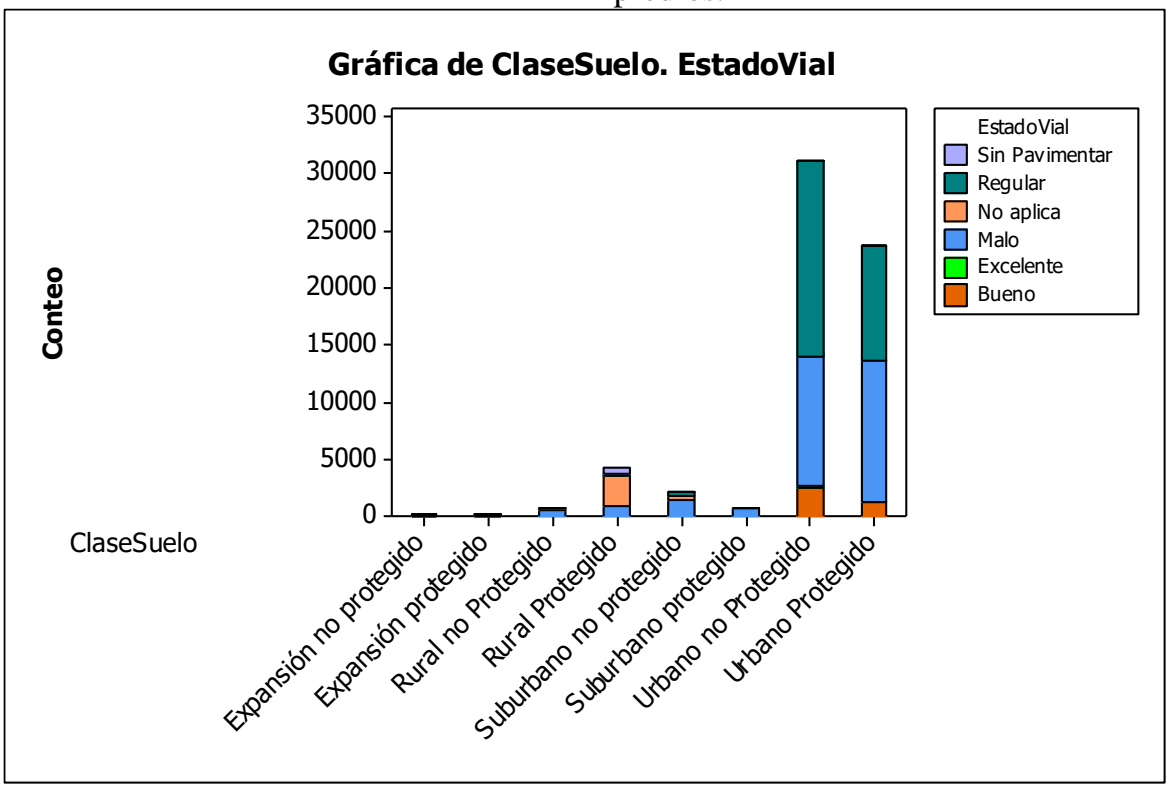

Figura 12. Relación entre Clase de suelo y Estado vial, en Medellín. Fuente: elaboración propia.

\section{Conclusiones}

De forma detallada, se analizaron 62918 predios informales, con los que se evidenció lo siguiente: en Medellín la mayor cantidad de asentamientos informales pertenecen a los estratos 1 y 2 contando con el 91,45\% de los predios totales, algunas de las descripciones de los usos de los predios son residencial, comercial y servicios, equipamentos, industrial, lotes y recreativo y deportivo, donde el $97 \%$ de los predios pertenecen a la categoría de tipo residencial. Adicional a ello, la ciudad cuenta con 4 clases de suelo: urbano, rural, de expansión y suburbano, subdivididos en territorios protegidos y no protegidos. La mayor cantidad de asentamientos informales en Medellín están ubicados en terrenos inclinados, ya sean ligeramente inclinados (entre 11 y $25 \%$ ), inclinados (entre 26 y $40 \%$ ) y ligeramente escarpado (entre 41 y 60 $\%)$, las tres clasificaciones mencionadas representan el $76,39 \%$ de los predios en la ciudad. El 91,66\% de los asentamientos informales en Medellín, cuenta con los servicios públicos conectados y en servicio continuo. Los estados viales en la ciudad son clasificados como excelentes, buenos, regular, malo y sin pavimentar en el que el $87,35 \%$ de las vías son regulares o malas, siendo estos porcentajes 44,54 \% y 42,80\% respectivamente. La mayor parte de los predios informales en la ciudad de Medellín poseen de 1 a 3 pisos y el 89,75\% de los predios informales en la ciudad cuentan con un único propietario.

Finalmente, se encontraron relaciones en los que la clase de suelo condiciona el estrato, la jerarquía vial y el estado vial en las distintas zonas de la ciudad. Debido que la informacion analizada en este documento fue obtenida por medio de contacto directo con la Subsecretaría de Catastro permiten conocer de forma verídica los comportamientos de la ciudad de Medellín. 


\section{Recomendaciones}

Para trabajos futuros se recomienda adquirir el acceso a la informacion adecuada con los entes regidores del país, para realizar investigaciones sobre temas en los que se concluyan con certeza los acontecimientos de la ciudad.

\section{Agradecimientos}

Se agradece a la Subsecretaría de Catastro por proporcionar toda la informacón que hizo posible este estudio.

\section{Referencias}

[1] B. C. Arimah, "Slums as expression of social exclusion: Explaining the prevalence of slums in African countries," in OECD International conference on social cohesion and development, Paris, 2001, pp. 201-21.

[2] R. Walpole, R. Myers and S. Myers, Probabilidad y estadística para ingenieros. Pearson Educación, 1999.

[3] P. Morales-Vallejo, Estadística aplicada a las ciencias sociales. Universidad Pontificia Comillas, 2000.

[4] J. Devore, Probabilidad y estadística para ingenierías y ciencias. International Thomson, 2008.

[5] F. J. Melgosa, "Impacto turístico, cultural e histórico del circuito turístico ecológico bolivariano Colombia Venezuela," tesis doctoral, Universidad de Salamanca, 2016.

[6] Alcaldía mayor de Bogotá, "Barrio | Unidad Administrativa Especial de Catastro Distrital - UAECD."

[7] "Barrios de Medellin," Wikipedia, 2018. [En línea]. Disponible en

https://es.wikipedia.org/wiki/Anexo:Barrios_de_Medellí

n. [Accedido: 26-enero-2018]

[8] “Catálogo de mapas,” Municipio de Medellín, 2018. [En línea]. Disponible en: https://www.medellin.gov.co/geonetwork/srv/spa/catalo g.search\#/home. [Accedido: 26-enero-2018]

[9] "Estratificación Socioeconómica," DANE, 2017. [En línea]. Disponible en: https://www.dane.gov.co/index.php/servicios-alciudadano/servicios-de-informacion/estratificacionsocioeconomica. [Accedido: 01-nov-2017]

[10] "Estratificación Socioeconómica - Preguntas Frecuentes," DANE, 2017. [En línea]. Disponible en: http://dane.gov.co/index.php/116-espanol/informacion- georreferenciada/2421-estratificacion-socioeconomicapreguntas-frecuentes. [Accedido: 01-nov-2017]

[11]"Glosario Certificado Catastral," Alcaldía de Medellín, 2017. [En línea]. Disponible en: https://www.medellin.gov.co/irj/go/km/docs/wpccontent /Sites/Subportal\%20de1\%20Ciudadano/Hacienda/Seccio nes/Publicaciones/Documentos/2012/Glosario\%20Cédu las\%20Catastrales.pdf 2017. [Accedido: 01-nov-2017]

[12]Subsecretaría de Hacienda, "Manual Zonas Homogeneas Fisicas Urbanas Medelllin 2008.” p. 63, 2009.

[13]Dirección de Planeación Institucional y Calidad, "GLOSARIO. Secretaría Distrital de Salud," vol. 132, p. 74, 2017.

[14]"Área Construida | Unidad Administrativa Especial de Catastro Distrital - UAECD," Alcaldía mayor de Bogotá, 2017. [En línea]. Disponible en: https://catastroenlinea.catastrobogota.gov.co/CatastroBo gota/. [Accedido: 01-nov-2017]

[15]"Inscripción Catastral | Unidad Administrativa Especial de Catastro Distrital - UAECD," Alcaldía mayor de Bogotá, 2017. [En línea]. Disponible en: https://www.catastrobogota.gov.co/. [Accedido: 01-nov2017].

[16]D. C. Montgomery, E. A. Peck, G. G. Vining, and V. G. Pozo, Introducción al análisis de regresión lineal. Editorial Continental, 2004. 
Anexo 1. Explicación para la clasificación de zonas protegidas en la ciudad de Medellín. Secretaría de Hacienda, Subsecretaría de Catastro (2009).

\begin{tabular}{|c|c|}
\hline Área & Descripción \\
\hline $\begin{array}{l}\text { Áreas de aptitud } \\
\text { forestal }\end{array}$ & $\begin{array}{l}\text { Son áreas de aptitud forestal la zona de propiedad pública o privada reservada para destinarla } \\
\text { exclusivamente al establecimiento o mantenimiento y utilización racional de áreas forestales } \\
\text { protectoras, protectoras - productoras, de acuerdo con las características y propiedades del suelo y su } \\
\text { ubicación en el Municipio. Las áreas de aptitud forestal tienen una importancia trascendental en la } \\
\text { conservación y preservación de especies, hábitat y ecosistemas, forman parte de los elementos } \\
\text { estructurantes de carácter físico y determinan la utilización del suelo a la siembra de especies forestales. }\end{array}$ \\
\hline $\begin{array}{c}\text { Áreas de } \\
\text { Protección a } \\
\text { nacimientos de } \\
\text { corrientes naturales } \\
\text { de agua } \\
\end{array}$ & $\begin{array}{l}\text { Es el área donde las aguas subterráneas afloran o brotan en forma natural, dando origen a manantiales } \\
\text { y corrientes de agua. Se definen como áreas de protección de nacimiento de corrientes naturales de } \\
\text { agua, las áreas circundantes a dichos afloramientos. Para los nacimientos de quebradas la faja de retiro } \\
\text { será de cien (100) metros a la redonda, medidos a partir de su periferia de conformidad con lo señalado } \\
\text { en las normas superiores, sin perjuicio de lo que defina la autoridad ambiental. }\end{array}$ \\
\hline $\begin{array}{l}\text { Retiros a corrientes } \\
\text { naturales de agua }\end{array}$ & $\begin{array}{l}\text { Se entiende por zonas de retiro, las fajas laterales de terreno a ambos lados de las corrientes, paralelas } \\
\text { a las líneas de máxima inundación o a los bordes del canal natural o artificial, cuyas funciones básicas } \\
\text { son: servir como faja de protección contra inundaciones y desbordamientos y conservar el recurso } \\
\text { hidrológico; brindar estabilidad para los taludes laterales que conforman el cañón de la corriente } \\
\text { natural; adecuar posibles servidumbres de paso para la extensión de redes de servicios públicos y } \\
\text { mantenimiento del cauce y proporcionar áreas ornamentales, de recreación y para senderos peatonales } \\
\text { ecológicos. } \\
\text { Estas áreas de protección se establecen para garantizar la permanencia de las fuentes hídricas naturales; } \\
\text { por lo tanto, no se pueden edificar, ya que su fin es la protección, el control ambiental y el constituirse } \\
\text { como faja de seguridad ante amenazas hídricas. } \\
\text { La dimensión de estos retiros es variable, partiendo de un retiro mínimo de protección de diez (10) } \\
\text { metros a una estructura hidráulica y quince (15) metros, medidos a partir del borde de la cota máxima } \\
\text { de inundación de la corriente natural, si se tienen registros hidrológicos, o en su defecto con relación a } \\
\text { los bordes superiores del canal natural (cauce y cañón) o artificial, hasta fajas máximas de treinta (30) } \\
\text { metros. }\end{array}$ \\
\hline $\begin{array}{l}\text { Zonas de alto } \\
\text { riesgo no } \\
\text { recuperable }\end{array}$ & $\begin{array}{l}\text { Son aquellas áreas urbanas o rurales, en gran parte ocupadas con vivienda que por su conformación } \\
\text { topográfica de altas pendientes, características hidrogeológicas o por la presencia de procesos de } \\
\text { inestabilidad geológica activos o latentes, por estar sometidas a una amenaza o riesgo externo, son } \\
\text { altamente inestables y de difícil tratamiento para su recuperación; así como aquellos terrenos ubicados } \\
\text { en márgenes de quebradas o ríos y en planicies de inundación carentes de obras de protección y que no } \\
\text { son aptas para la localización de asentamientos humanos. }\end{array}$ \\
\hline $\begin{array}{l}\text { Zonas de riesgo } \\
\text { recuperable }\end{array}$ & $\begin{array}{l}\text { Las zonas caracterizadas como de moderadas restricciones geológicas o potencialmente inestables y de } \\
\text { nivel de riesgo medio o bajo, se delimitarán e identificarán como áreas recuperables y podrán ser objeto } \\
\text { de programas de titulación y de reordenamiento en su infraestructura básica. El manejo de estas áreas, } \\
\text { así como las obras que se requieren para su recuperación, están condicionados a las características } \\
\text { particulares de cada terreno y de la infraestructura existente. } \\
\text { Estas zonas podrán ser objeto de programas de reordenamiento urbanístico, cubrimiento con servicios } \\
\text { públicos básicos, mejoramiento barrial, titulación y otorgamiento de licencias de construcción, una vez } \\
\text { hayan sido reducidos los niveles de amenaza con obras de protección específicas. }\end{array}$ \\
\hline $\begin{array}{l}\text { Áreas de reserva } \\
\text { para la ubicación } \\
\text { de servicios } \\
\text { Públicos }\end{array}$ & $\begin{array}{l}\text { Con el fin de establecer las disposiciones y criterios que faciliten la ubicación futura de redes de } \\
\text { servicios públicos, o las servidumbres requeridas para el efecto, se determinarán por parte de las } \\
\text { empresas prestadoras de los mismos, las áreas de reserva que se precisen para la ubicación futura de } \\
\text { infraestructuras de servicios públicos. Estas áreas deberán consultar los estudios técnicos } \\
\text { correspondientes a los futuros proyectos viales, o la ampliación de las vías existentes. }\end{array}$ \\
\hline $\begin{array}{l}\text { Reservas de la } \\
\text { Sociedad Civil }\end{array}$ & $\begin{array}{l}\text { De conformidad con la Ley } 99 \text { de } 1993 \text { se entiende como Reserva Natural de la Sociedad Civil la parte } \\
\text { o el todo del área de un inmueble que conserve una muestra de un ecosistema natural y sea manejado } \\
\text { bajo los principios de la sustentabilidad en el uso de los recursos naturales, cuyas actividades y usos se } \\
\text { establecerán de acuerdo con la reglamentación, con la participación de las organizaciones sin ánimo de } \\
\text { lucro de carácter ambiental. } \\
\text { Se excluyó de la categoría, las áreas en que se exploten industrialmente recursos maderables, } \\
\text { admitiéndose sólo la explotación maderera de uso doméstico y siempre dentro de parámetros de } \\
\text { sustentabilidad. }\end{array}$ \\
\hline
\end{tabular}


Anexo 2. Explicación para la jerarquía vial en la ciudad de Medellín. Secretaría de Hacienda, Subsecretaría de Catastro (2009).

\begin{tabular}{|c|c|}
\hline Jerarquía vial & Descripción \\
\hline Sin Vías & Se utiliza para aquellas zonas donde no se presenta ningún tipo vía. \\
\hline Vía Férrea & $\begin{array}{l}\text { Constituyen el sistema de vías de carrilera, para la operación de trenes correspondiente a la red } \\
\text { ferroviaria nacional. Poseen prelación sobre cualquier otra vía. }\end{array}$ \\
\hline $\begin{array}{l}\text { Sistema Metro Líneas } \\
\text { A y B }\end{array}$ & $\begin{array}{l}\text { Constituyen el sistema de vías de carrilera y sus estaciones que permiten la operación de trenes. En } \\
\text { la ciudad corresponden a las líneas A, B y la de enlace del metro. }\end{array}$ \\
\hline $\begin{array}{l}\text { Sistema Metrocable } \\
\text { Líneas J y K }\end{array}$ & $\begin{array}{l}\text { Constituyen el sistema de vías de transporte por cable aéreo, para la operación de cabinas de } \\
\text { pasajeros. En la ciudad corresponden a las líneas J y K, del Metrocable. }\end{array}$ \\
\hline Sistema Metroplús & $\begin{array}{l}\text { Vías con destinación exclusiva de carriles y/o calzadas para el tránsito de servicio público masivo. } \\
\text { Pertenecen a este sistema todas las vías utilizadas para implementar el transporte masivo de } \\
\text { mediana capacidad. }\end{array}$ \\
\hline Autopista Urbana & $\begin{array}{l}\text { Son vías rápidas de alta capacidad y largo recorrido, que se caracterizan por tener calzadas } \\
\text { separadas, accesos y salidas controladas, y todas sus intersecciones a desnivel. } \\
\text { En Medellín, el único eje con características de autopista urbana es el sistema vial del corredor } \\
\text { multimodal de transporte del río Medellín (Aburrá). }\end{array}$ \\
\hline $\begin{array}{l}\text { Vías Arteriales } \\
\text { Principales }\end{array}$ & $\begin{array}{l}\text { Su función principal es movilizar el flujo vehicular de largo recorrido dentro del área urbana, } \\
\text { uniendo entre sí las diferentes zonas de la ciudad. } \\
\text { El sistema vial arterial principal para la ciudad de Medellín estará conformado por el anillo } \\
\text { bidireccional del centro, un sistema de vías en dirección norte-sur que corresponde casi totalmente } \\
\text { al sistema vial metropolitano, y un sistema de vías en dirección oriente-occidente, que cruza a } \\
\text { desnivel sobre el sistema vial del río Medellín (Aburrá). } \\
\text { Ver específicamente las vías en: [12] Pag } 39 \text {. }\end{array}$ \\
\hline $\begin{array}{c}\text { Vías Arteriales } \\
\text { Menores }\end{array}$ & $\begin{array}{l}\text { Cumplen funciones similares a las vías arterias principales y en algunos casos presentan } \\
\text { características semejantes a éstas, pero con menor alcance (longitud). } \\
\text { Ver específicamente las vías en: [12] Pag } 41 \text {. }\end{array}$ \\
\hline Vías Colectoras & $\begin{array}{l}\text { Es el conjunto de vías que distribuyen y canalizan el tránsito vehicular hacia o desde el sistema } \\
\text { arterial hasta diferentes sectores urbanos, en forma directa o con intervención complementaria de } \\
\text { las vías de servicio. Generalmente unen vías arterias entre sí, y deben atender volúmenes de tránsito } \\
\text { moderados, incluyendo el transporte público colectivo. }\end{array}$ \\
\hline Vías de Servicio & $\begin{array}{l}\text { Es el conjunto de vías vehiculares cuya función principal es facilitar el acceso directo a las } \\
\text { propiedades o actividades adyacentes, perdiendo importancia la función de movilidad. } \\
\text { Para este sistema de vías debe restringirse (en lo posible) el transporte público y de carga, y la } \\
\text { velocidad permitida estará condicionada al desarrollo de las actividades y flujos peatonales } \\
\text { existentes. }\end{array}$ \\
\hline $\begin{array}{l}\text { Vías Peatonales de } \\
\text { Transito urbano }\end{array}$ & $\begin{array}{l}\text { Vías en donde no se permite el paso vehicular, por características inherentes a la vía como sus } \\
\text { dimensiones, o que poseen obstáculos para el paso de los mismos, presentan un amplio tránsito } \\
\text { peatonal urbano, conducen a accesos peatonales más pequeños. }\end{array}$ \\
\hline $\begin{array}{l}\text { Vías Peatonales de } \\
\text { acceso a vivienda }\end{array}$ & $\begin{array}{l}\text { Son aquellas vías excluidas del tránsito vehicular que permiten exclusivamente el acceso peatonal } \\
\text { a los predios, por lo general son vías estrechas o corredores que en su mayoría se presentan en } \\
\text { barrios de la periferia de la ciudad, generalmente se llega a ellos mediante una Vía Peatonal de } \\
\text { Transito Urbano. }\end{array}$ \\
\hline $\begin{array}{l}\text { Vías Peatonales } \\
\text { Escalonadas }\end{array}$ & $\begin{array}{l}\text { Son aquellas vías que permiten exclusivamente el acceso peatonal a viviendas en donde su } \\
\text { estructura son escaleras en pavimento, por lo general son vías estrechas o corredores que en su } \\
\text { mayoría se presentan en barrios de la periferia de la ciudad. }\end{array}$ \\
\hline
\end{tabular}

